\title{
The Heavy Lifting of Diversity: A Need for Scholar Administrators
}

\author{
Jacinta R. Saffold
}

\begin{abstract}
Technological innovation and new economic terrain of the twenty-first century has called for higher education to re-examine how interdisciplinary ethnic studies and minority serving programs are positioned in the twenty-first century. This essay considers the utility of spaces like Black Studies departments and programs like the Mellon Mays Undergraduate Fellowship within the structure of Liberal Arts education today from the vantage a recent graduate. In the wake increasing hostility towards minority students and unfavorable media coverage of incidents on campus, colleges and universities must consider how rolling back minority-focused academic and programmatic offerings alongside dramatic increases in contingent faculty and administrative staff hiring has left cultural voids. As Liberal Arts educators grapple with narrowing budget constraints and changing campus climates, the call for higher education employees who understand why disciplinary and programmatic offerings are tied to campus climate, and how to use such resources, grows louder. Scholar Administrators, in their ability to straddle the historic dividing line between faculty and staff, can help usher in a type of diversity that allows each student, faculty, and staff person to bear witness to the humanity in others, which ultimately is the heavy lifting of diversity.
\end{abstract}

Keywords: diversity; scholar administrator; contingent faculty; minority programs

\section{Introduction}

As a beneficiary of spaces won by college student activism during the Civil Rights Era, my place in academia is more than forty years in the making. I am the intellectual product of Liberal Arts education, two African American Studies departments, and several diversity and inclusion initiatives. In reflecting on my scholarly "up-bringing," I have come to understand that the lessons I learned on how to survive and thrive in Liberal Arts spaces as an African American woman were just as important as the academic training I received. I was fortunate enough to matriculate through departments that demanded students who would aspire to be more than diligent researchers, brilliant writers, and uncompromising knowledge producers. My professors unhinged the rigid boundaries of academic disciplines, so that I could freely explore the interconnectedness of history, literature, culture, politics, and beyond. In handing me intellectual freedom, African American Studies has also called me to produce scholarship that has meaning outside of the halls of academia, that can make the world a better place, and that will, in turn, free others from intellectual restrictions.

African American Studies at Emory University, the University of Massachusetts Amherst, and other colleges and universities were the result of undergraduate student protests and positive administrative responses during the late 1960s (Bradley, 2009, p.112; Hine, 2001, p.51; Christian, 2006, p.698-700). Demands for the inclusion of voices from the African Diaspora in 
all sectors of Liberal Arts education was an outgrowth of a national discourse on civil liberties. The spirit of the civil rights protest tradition influenced how newly formed Afro American, Africana, and African American Studies programs designed their curriculum. Many Black Studies ${ }^{1}$ departments adopted a scholar-activism approach to training students and made community engagement an integral part of the curriculum plan (Kershaw, 2003, p.28). The scholar-activist, by design, expects African American Studies scholarship to perform double duty, by meeting the same academic standards as longstanding disciplines and move discourse beyond the academy forward on issues effecting people of color.

The expectations of interdisciplinarity, especially for junior faculty coming from activist-forged departments, are further compounded by race, gender, and other socially constructed differences. Minority and interdisciplinary scholars focused on minority communities often struggle to reconcile their scholarly motivations, responsibility to outside communities, and expectations set forth by their college or university. Having institution personnel who work at the cross section of scholarly research, teaching, and administration can help ensure junior faculty are not forced to make reductive choices among their competing obligations. Scholar administrators can ensure that interdisciplinary departments and diversity initiatives achieve enough autonomy to withstand the changing priorities of the current administration. ${ }^{2}$ Further, crosscutting employees can help colleges and universities see the value of interdisciplinary and minority faculty add outside of traditional tenure expectations.

Colleges and universities need scholar administrators. The concept of a scholar administrator has been quite reactionary to this point. Higher education professionals who have spent their careers at the intersection of teaching, researching, and administration are heralded as scholar administrators and celebrated for their ability to provide gap services the university had not realized it needed at the close of their careers (Barthwal, 1991; Blegen, 1960; Billard \& Ferber, 1991). However, the demands of twenty-first century higher education are pointing towards a need to intentionally train PhDs to cross boundaries as a means of uniting institutions over the long-held faculty and staff divide to actually obtain sustainable and comprehensive employment in higher education.

When colleges and universities have incidents of hate or discrimination, interdisciplinary departments like African American Studies, Women Gender \& Sexuality Studies, and Chicana/o Studies usually support the university through the crisis by creating additional lectures, seminars, and special courses. Most of this extra labor goes unacknowledged when university administration informs the public about what steps have been taken to address the incident and ensure that such occurrences will not continue. If nooses are found hanging from trees, the university will point to a recently formed council on diversity and inclusion. ${ }^{3}$ If a university is

\footnotetext{
${ }^{1}$ Black Studies is used here as an umbrella term for the various kinds of departments that study people of the African Diaspora.

${ }^{2}$ Black Studies and people of color initiatives often live or die based on the level of investment the current Dean, provost, and or the president has in diversity.

${ }^{3}$ On May 1, 2017, several bananas were found hanging from nooses at American University with the words "Harambe Bait" and "AKA Free” written on the side. This was interpreted as a racially motivated crime in response to the election of the first African American woman student body president. American University president, Neil Kerwin stated that, "There will be a campus community meeting on Tuesday, May 2 to discuss the incident at 12
} 
shamed for not taking strong disciplinary action against sexual assault, the university will convene a committee to address sexual assault on campus. ${ }^{4}$ Interdisciplinary departments intentionally offer additional support to the campus to ensure that the university or college has a tangible and very public response to improper occurrences on campus; most of which is left out of press releases or university-wide communications. ${ }^{5}$ Minority and interdisciplinary faculty are often expected to serve on steering committees to address underlying forces that created the crisis. The offices of such faculty have also become sanctuaries for major and non-major students to unburden themselves of the baggage these incidents induce. These functions are not automatically viewed as academic labor and do not neatly fit into tenure portfolios. In fact, the additional steps interdisciplinary departments take to address issues are not usually acknowledged by the university in any formal way. So, faculty of color, particularly those housed in interdisciplinary departments, are expected to produce scholarship that has double functionality and perform more service, so that the university can do the work of dealing with intolerable injustices, while delivering a similar quantity and quality of scholarship and students enrolled in classes as all the other disciplines on campus.

The consequences for failing to meet these impossible expectations are also higher than other disciplines, simply because interdisciplinary programs and departments are almost always the last to be funded and the first to be rolled back or eliminated during economic downturns (Rhodes, 2016; Rooks, 2006). Holding interdisciplinary programs to ambitious standards is not the issue and should, in fact, be the expectation. However, many interdisciplinary programs are often held to different and competing standards that force faculty to shrink from their original purpose; African American Studies departments choosing between scholarship and supporting student activism, for example. Until colleges and universities begin intentionally aggregating their expectations for scholarship and service to equitably reflect the purposes and expectations of different disciplines, interdisciplinary departments and the students, communities, and wide publics they serve will suffer. Scholar administrators act as interlocutors who can ensure that the unique expectations of interdisciplinary programs are not lost or forgotten.

Economic pressure compounds the unequal labor distribution among faculty, by simultaneously pricing many Americans out of higher education and dramatically reducing the number of available tenure track faculty positions for teaching at Liberal Arts institutions (Kelsky, 2015, p.7). The American Association of University Professors has reported that, "the share of fulltime tenured faculty has declined by approximately 26 percent since 1975, while the share of tenure-track faculty has declined by nearly 50 percent” (2017, p.4). The economic and

noon in Kay Chapel. Members of the President's Council on Diversity and Inclusion (PCDI) will be in attendance.” (http://www.american.edu/president/announcements/May-1-2017.cfm)

${ }^{4}$ In 2014 Dartmouth College was accused of mishandling sexual harassment and violence cases on campus. In response, the college created an initiative, "Moving Dartmouth Forward” which is “aimed at eliminating high-risk behavior and increasing inclusivity while strengthening Dartmouth’s longstanding commitment to leadership in teaching and learning.” (http://forward.dartmouth.edu/)

${ }^{5}$ For example when black and brown students had racial slurs written on their dormitory doors at the University of Massachusetts Amherst in 2014, The W. E. B. Du Bois Department of Afro American Studies hosted a series of open dialogues in the Malcolm X Cultural Center (housed in the largest on-campus living community), designed and taught special seminars on race and difference through the Residential Academic Programs (RAP) Academy, and held a special training session on how to discuss difficult subjects in African American Studies course with graduate teaching assistants. None of these activities were listed in the university-wide communication from the Chancellor detailing how the university would respond to the incident. 
employment crunch in higher education is also indicative of wider employment shifts in the United States. The twenty-first century has ushered in the use of smart technology that has radically reduced and restructured employment needs across occupations. Specific to higher education, this has led to the establishment of contingent positions like adjunct professors, visiting lecturers, and postdoctoral teaching fellows, in lieu of traditional tenure track opportunities. In 2016-2017, "faculty members on part-time appointments continued to make up the largest share of the academic labor force,” with an average annual total pay of \$20,508 according to the 2016-17 Annual Report on the Economic Status of the Profession. Financial squeezing from students unable to afford tuition ${ }^{6}$ and cuts to fiscal operating budgets is forcing colleges and universities to be more creative in their approach to hiring employees. For faculty of color, who are already overburdened with unrecognized service to the profession, this can mean amending the adage of twice as good to three times or more. ${ }^{7}$ Contrarily, if employment reconfigurations in higher education are done with deliberate emphasis and by people who recognize the value of cross-cutting service work performed by minority faculty and interdisciplinary departments, these transformative people and spaces can finally be moved from the periphery of our colleges and universities to the center. This shift has the potential to truly transform Liberal Arts education in the twenty-first century.

As many colleges and universities begin to rely more on contingent faculty to answer shifts in the higher education employment landscape, there must be critical oversight on the effectiveness of this strategy. Further, colleges and universities must be willing to revamp structures if they are proven ineffective. In 2014, the Institute for Research and Study of Accreditation and Quality Assurance reported:

Whereas full-time tenured and tenure-track faculty were once the norm, the professoriate is now comprised of mostly non-tenure-track faculty. In 1969, tenured and tenure-track positions made up approximately 78.3 percent of the faculty and non-tenure-track positions comprised about 21.7 percent. Forty years later, in 2009, these proportions had nearly flipped” (2014, p.4).

On average, part-time lecturers - the largest group of contingent faculty members-earn \$16,700 from teaching alone per year compared to an average of $\$ 67,000$ per year for the lowest rank of tenure track faculty (Griffey, 2016). In addition to a grave reduction in pay, contingent faculty hiring is often an informal process devoid of job security. These contingent faculty positions often leave the employee on the brink of poverty, in a constant state of flux, and makes the cost of earning the requisite Master's and/or PhD for collegiate teaching a bad investment. These positions cannot be long-term solutions for colleges and universities, because job instability and being embarrassingly underpaid will cause our colleges and universities to lose the brightest and best new advanced degree holders to tech start-ups, non-profit organizations, federal agencies, and large business corporations. As for the university, temporary and underpaid teaching positions serve to further isolate already siloed departments, programs, schools, and colleges (Umber, 2014).

\footnotetext{
${ }^{6}$ According to Mitchell, Palacios, and Leachman, the average annual published tuition has risen 28 percent from 2007 to 2014 ("States are Still Funding," 10).

${ }^{7}$ The adage explains that people of color must be twice as good as their peers to get half as far.
} 
Due to the increase of non-tenure track academic positions, the employment crunch has increased the competitiveness of the tenure track job market and severely truncated the kinds of scholars that universities and colleges are looking to hire (Mitchell, Palacios, \& Leachman, 2014). Colleges and universities are more unwilling than ever to take a chance on brilliant scholars who are looking to push disciplinary boundaries. Instead, many institutions are simply looking for the cheapest way to instruct students, which often neglects to foment the process of discovery that is at the heart of Liberal Arts education. Rejections of full-time faculty are losses of scholarly creativity and reductions in areas of academic expertise, especially for interdisciplinary subjects, which are felt campus-wide every time an institution is admonished publicly for failing to meet the specific needs of its various minority groups. Colleges and universities seeking to revise employment structures to increase efficiency in Liberal Arts education must promote creative and comprehensive problem-solving among their faculty and staff to ensure that all student needs are met. It is through creativity in employment configuration that higher educational professionals will strike a balance between meeting financial constraints and providing the best education for the world's future leaders.

Increasingly, faculty members engaged in interdisciplinary or ethnic area studies scholarship are being jointly appointed to two or more departments to encourage multidisciplinary approaches to complex questions. Joint appointments are also very practical responses to the money crisis (Patton, 2015). New faculty members often have service obligations to multiple departments, programs and/or centers that are affiliated with their home department(s), in addition to their teaching and research duties. For junior faculty of color, the service load is often further exacerbated by supporting minority students and minority-serving programs. Many of the service roles new faculty are asked to fill were once defined as staff roles. This conflation of faculty and staff roles is potentially dangerous in its willful ignorance of overloading junior faculty and making coveted tenure more elusive. However, the broadening of faculty responsibilities has the potential to make desperately needed cross cutting connections around campus. These multidisciplinary roles allow for campus communities to unify across the great faculty, staff divide that has kept many of our colleges and universities from reaching their fullest potential. The concept of integrating faculty and staff duties is positive, but only if colleges and universities are careful not to overburden employees.

Diversity and inclusion programs for students often face similar points of contention on college and university campuses. My path in academia was forged by programmatic spaces that specifically bridged economic, social, and experience gaps for students of color. ${ }^{8}$ Some spaces were intended to be safe spaces to ensure that students of color could convene without retribution, others were designed to help us stay connected to our various communities outside of the university, while others attempted to alleviate stressors that traditionally prohibit academic success for minority students. Student groups like Ngambika, a step ${ }^{9}$ and community service organization for freshman women of color at Emory University, and multi-ethnic achievement

\footnotetext{
${ }^{8}$ Programs for supporting African American students' unique challenges and needs was directly connected to student protests for the creation of Black Studies departments in the late 1960s (Bradley, 2009, p.115).

${ }^{9}$ Stepping is rhythmic form of movement and music derived from synchronized hand claps and foot stomps that is popular among Black Greek Letter Organizations and African American college students.
} 
programs like the Mellon Mays Undergraduate Fellowship (MMUF), ${ }^{10}$ are often created in vacuums. Often, these initiatives are housed in ethnic area studies departments, multicultural centers, or diversity offices and are designed to partially remove negative variables that disproportionately impact students of color, to alleviate the added pressure on students of color, and encourage academic success. The Woodrow Wilson Foundation has reported that, "doctoral education's diversity record is poor" generally. One of the foundation's recommendation for improvement is to bolster communication among programs for academic diversification. In addition to strengthening cross dialogue among programs like MMUF, McNair Scholars, and Gates Millennium Scholars, I contend that these programs need to be better integrated into the core of hosting college and university. Keeping such programs at the margins or as an offshoot of one department has the potential to devalue the work of these initiatives. Such programs often struggle with becoming fully integrated into the college or university because diversity is not necessarily always mandatory or the expectation for excellence throughout campus.

Diversification programs that help minority students, faculty, and staff navigate the politics of race, gender, and class are some of the biggest incubator spaces on campuses across the country. Interdisciplinary departments and diversity programming are often vibrant and inclusive spaces that are also insular from the tumultuous climate of the wider university. These programs risk teaching participants how to operate in the kinds universities we would like to see- that are diverse and inclusive-rather than the ones that currently exist. Diversity and inclusion programming beneficiaries are often sent into collegiate settings that lack the foundation to support them. Though the incubator method has been established as the industry standard, this model is one born of resistance rather integration. Resistance is tiresome work that is not sustainable.

An independent study conducted by researchers at the Cornell Higher Education Research Institute, indicates that MMUF has not made a measurably significant difference in minorities obtaining the $\mathrm{PhD}$. However, the study also states that participating in MMUF has improved the quality of experience for minority students in doctoral programs. This is further evidenced by the MMUF 25th Anniversary report claiming that MMUF participants finish their doctoral programs up to three years faster than the national average. For programs like MMUF to live up to their mission of increasing diversity in the professoriate, our colleges and universities must first see the value in diversification and agree to intentionally work toward ensuring that there is room on department faculty rolls when minority candidates complete the PhD. According to Brad Rose Consulting, "gaining and sustaining support from, and recognition by, host institutions" is one of the major challenges MMUF faces (13). MMUF, and programs like it, need to be streamlined with the stewarding of the college or university, so that supporting minority students through academic training is not another burden only managed by overworked minority faculty and under-resourced interdisciplinary departments. Streamlining will require the help of faculty and high-ranking administrative staff. This kind of work is ripe for scholar administrators.

The goal should be to make our campuses so diverse and inclusive that special support programs are no longer ancillary but an integral thread in the university’s fabric. To achieve such equity,

\footnotetext{
10 The Mellon Mays Undergraduate Fellowship specifically addresses underrepresentation in the academy by helping minorities acquire doctoral degrees in the Humanities and Social Sciences.

http://www.mmuf.org/about/mission
} 
we must shift how minority students, faculty, and staff are received by the wider university rather than training them to resist the pressures of being different in a collegiate setting.

Admittedly, this an incredible, utopian even, undertaking. Having designated appointees who understand the import and have the will to fight for the reconfiguration of unequitable policies on campus in positions to make real changes to antiquated processes for the college or university is one step in the right direction.

Research shows that colleges and universities have begun to hire more administrative staff (Hurlburt \& McGarrah, 2016; McElroy, 2017). This shift has been characterized as adopting corporate business models for operating Liberal Arts institutions. When a growing administration is coupled with an over-reliance on contingent faculty, the university model becomes lopsided and dysfunctional. According to the American Institutes for Research study on Contingent Faculty, private four-year colleges and universities realized the largest decline in instructional spending of all tuition types. The report also determined that constraining faculty compensation modestly impacted overall employee spending (Hurlburt \& McGarrah, 2016). Many colleges and universities are simply shifting their dollars from highly trained faculty to high-level administrators. This war for resources between faculty and staff leaves the students underserved and with hefty tuition bills. Rather than choosing between faculty and staff_-both of which are essential to operating our colleges and universities - we must consider how these two roles can overlap or merge. Making efficient personnel decisions will allow our schools to have the best administrators, brightest scholars, and a reduced operating budget.

The time has come for higher education to begin training our graduate students to be scholar administrators. The role of scholar-administrators demands (and opportunity calls for) people who can fill non-traditional roles aimed at integrating the various sectors of a college or university. We are living in a global society that values connectedness and efficiency. It is the duty of our colleges and universities to help the people of the world learn how to talk across difference. It is not enough to be diverse in representation - that is not the heavy lifting of diversity. Rather, finding a common language that allows each of us to bear witness to the humanity in others is the real challenge, especially for colleges and universities. 


\section{References}

The Andrew W. Mellon Foundation. (2013). Report of the Andre W. Mellon Foundation, 2013. Retrieved from https://mellon.org/media/filer_public/a6/51/a6515255-46f3-4b6f-9b4ab1f1d0ef1205/awmf-ar-2013.pdf

Shulman, S et al. (2017, March-April). Visualizing change: The annual report on the economic status of the profession, 2016-17. Academe, 103(2), 4. Retrieved from https://www.aaup.org/file/FCS_2016-17_nc.pdf

Barthwal, C. P. (1991, April-June). Professor P. N. Masaldan: Scholar, administrator and a humanist. The Indian Journal of Political Science, 52(2), 279-281. Retrieved from https://www.ijps.net.in/ijps_publication.php

Billard, L. \& Ferber, M.A. (1991, May). Elizabeth Scott: Scholar, teacher, administrator. Statistical Science, 6(2), 206-216. https://doi.org/10.1214/ss/1177011828

Blegen, T.C. (1960, June). Solon Justus Buck: Scholar-administrator. The American Archivist, 23(3), 259.262. https://doi.org/10.17723/aarc.23.3.r002351385235312

Bradley, S.M. (2009). Black student power: The struggle for black studies. In Harlem vs. Columbia University: Black Student Power in the Late 1960s. University of Illinois Press.

Christian, M. (2016, May). Black Studies in the $21^{\text {st }}$ Century: Longevity Has Its Place. Journal of Black Studies, 36(5), 698-719. https://doi.org/10.1177/0021934705285939

Curtis, J.W. \& Thornton, S. (2013). Here's the news: The annual report on the economic status of the profession, 2012-13. Academe, 99(2), 4. Retrieved from https://www.aaup.org/sites/default/files/files/2013\%20Salary\%20Survey\%20Tables\%20and\%20 Figures/report.pdf

Griffey, Tr. (2016, September 2). Decline of tenure for higher education faculty: An introduction. The Labor and Working-Class History Association. Retrieved from https://www.lawcha.org/2016/09/02/decline-tenure-higher-education-faculty-introduction/

Hine, D. C. (2001). Black studies: An overview. In N. Norment, Jr. (Ed.), The African American Studies Reader (pp. 50-57). Durham, NC: Carolina Academic Press.

Hurlburt, S. \& McGarrah, M. (2016). Cost savings or cost shifting? The relationship between part-time contingent faculty and institutional spending. Retrieved from http://www.air.org/resource/cost-savings-or-cost-shifting-relationship-between-part-timecontingent-faculty-and

Institute for Research and Study of Accreditation and Quality Assurance. (2014.) An examination of the changing faculty: Ensuring institutional quality and achieving desired student 
learning outcomes. CHEA Occasional Paper. Retrieved from

https://www.chea.org/userfiles/Occasional\%20Papers/Examination_Changing_Faculty_2013.pdf

Kelsky, Karen. The Professor is in: The essential guide to turning your PhD into a job. New York, NY: Three Rivers Press. 2015.

Kershaw, T. (2003). The black studies paradigm: The making of scholar activists. In James Conyers, Jr. (Ed.), Afrocentricity and the Academy: Essays on Theory and Practice, (p.27). Jefferson, N.C.: McFarland \& Company, Inc. 2003.

McElroy, W. (2017, June 16). Administrative bloat on campus: Academia shrinks, students suffer.” The James G. Martin Center for Academic Renewal. Retrieved from https://www.jamesgmartin.center/2017/06/administrative-bloat-campus-academia-shrinksstudents-suffer/

Mitchell, M., Palacios, V., Leachman, M. (2014). States are still funding higher education at prerecession levels. Center on Budget and Policy Priorities. Retrieved from https://www.cbpp.org/sites/default/files/atoms/files/5-1-14sfp.pdf

Patton, S. (2015). How joint appointments stall the careers of ethnic-studies professors. Chronicle Vitae. Retrieved from https://chroniclevitae.com/news/994-how-joint-appointmentsstall-the-careers-of-ethnic-studies-professors

Prenovitz, Sarah J. et al. An evaluation of the Mellon Mays Undergraduate Fellowship's effect on PhD production at non-uncf institutions. Cornell Higher Education Research Institute.

Retrieved from https://www.ilr.cornell.edu/sites/ilr.cornell.edu/files/cheri-wp-161.pdf

Rhodes, Dawn. (2016, September 6). Black studies struggle at state universities under current fiscal climate. Chicago Tribune. Retrieved from

http://www.chicagotribune.com/news/local/breaking/ct-african-american-studies-college-majormet-20160905-story.html

Rooks, Noliwe. White Money/Black Power: The Surprising History of African American Studies and the Crisis of Race in Higher Education. Boston: Beacon Press. 2006.

Rose, Brad. Program Review: The Mellon Mays Undergraduate Fellowship (MMUF) program. Brad Rose Consulting, Inc. 2007. Retrieved from https://bradroseconsulting.com/wpcontent/uploads/2012/10/MMUF-Program-Review.pdf

Umber, A. [Pseud.]. (2014, August 20). I used to be a good teacher. Retrieved from https://chroniclevitae.com/news/668-i-used-to-be-a-good-teacher

The Woodrow Wilson National Fellowship Foundation. (2005, May). Diversity \& the PhD: A review of efforts to broaden race \& ethnicity in U.S. doctoral education. Retrieved from

http://www.uky.edu/ie/sites/www.uky.edu.ie/files/uploads/Diversity\%20\%26\%20the\%20PhD\%20A\%20

Review\%20of\%20Efforts\%20to\%20Broaden\%20Race\%20\%26\%20Ethnicity\%20.\%20.\%20..pdf 


\section{Author Information}

Jacinta R. Saffold is a Mellon ACLS Public Fellow at the Association of American Colleges and Universities where she serves as the Associate Director for Diversity, Equity, and Student Success in the Office of Diversity, Equity, and Student Success. Her work focuses on building Truth, Racial Healing \& Transformation campus centers with colleges and universities across the United States. She has been researching critical issues at the cross section of race, gender, and culture for more than a decade.

Jacinta R. Saffold, PhD

Associate Director for Diversity, Equity, and Student Success

Mellon ACLS Public Fellow

Association of American Colleges \& Universities

Email: Saffold@aacu.org 